\title{
Fatores naturais na evolução das paisagens no município de Tejuçuoca, Ceará, Brasil
}

\author{
Natural factors in the evolution of the landscape in the municipality of Tejuçuoca, Ceará, \\ Brazil
}

\author{
Bastos $^{1}$, F. H.; Cavalcante ${ }^{2}$, D. R.; Silva $^{3}$, E. V. \\ fred.holanda@uece.br
}

\begin{abstract}
Resumo
O município de Tejuçuoca localiza-se na microrregião do médio Curu, região Norte do Estado do Ceará, possuindo uma área de aproximadamente $750 \mathrm{Km}^{2}$, sendo composto pela sede municipal de Tejuçuoca e Caxitoré, seu único distrito. O objetivo do referido trabalho é analisar de forma preliminar o quadro natural em que o município de Tejuçuoca está inserido. Para chegar ao objetivo proposto foram realizados levantamentos bibliográficos e cartográficos, bem como trabalhos de campo no município em questão. No que diz respeito aos seus aspectos geológicos, o referido município possui substrato litológico do Complexo Ceará, com predominância de rochas das unidades Canindé e Independência, onde há primazia de rochas metamórficas datadas do précambriano. Observou-se a depressão sertaneja como principal feição geomorfológica, além dos relevos residuais, as planícies fluviais e os relevos cársticos. O clima apresenta condições semiáridas, tendo altas temperaturas com poucas variações anuais e chuvas irregulares ao longo do ano. O mosaico de solos do município é bastante variado, com destaque para os neossolos, argissolos, luvissolos e planossolos. A vegetação de caatinga apresenta-se em bom estado de conservação com significativas variações fisionômicas e florísticas.
\end{abstract}

Palavras-chave: Natural; Relevo; Conservação.

\begin{abstract}
The Tejuçuoca municipality located in the middle Curu micro region, north of Ceará, having an area of approximately $750 \mathrm{Km}^{2}$, and is composed by the city of Tejuçuoca and Caxitoré his single district. The objective of this study is to analyze in a preliminary way the natural environment of the municipality of Tejuçuoca. To reach the proposed objective were made bibliographic and cartographic surveys and field work in the municipality. With respect to its geological aspects, the municipality has lithological substrate of Ceará complex with predominance of rocks of units Caninde and Independence, where there is primacy of metamorphic rocks dating of Precambrian. There was the sertaneja depression as a major geomorphological feature, in addition to residual relief, river plains and karst reliefs. The weather has semi-arid conditions, with high temperatures with few annual variations and irregular rainfall throughout the year. The mosaic of soils in the municipality is significantly varied, highlighting the leptosols, acrisols, luvisols and planosols. The vegetation of caatinga is presented in good condition of conservation with significant physiognomic and floristic variations.
\end{abstract}

Keywords: Natural. Relief. Conservation.

\section{INTRODUÇÃO}

Bastos e Cordeiro (2012) destacam que os processos envolvidos na elaboração das paisagens, envolvem uma notável complexidade natural, demandando assim, uma perspicácia acurada do pesquisador junto a um censo crítico para identificar o verdadeiro papel de cada componente ambiental. 
Neste contexto, para se realizar pesquisas de cunho ambiental, numa perspectiva holística, são necessários estudos setorizados, onde se fazem abordagens dos diferentes componentes ambientais para subsidiar análises integradas mais complexas.

A ausência de estudos de cunho ambiental no município de Tejuçuoca é fato. Com isso, se faz necessário um estudo com uma abordagem preliminar sobre seus componentes ambientais, buscando subsidiar estudos futuros em diversas áreas do conhecimento.

O município de Tejuçuoca (Figura 1) localiza-se na microrregião do médio Curu, região Norte do Estado do Ceará, possuindo uma área de aproximadamente $750 \mathrm{Km}^{2}$, sendo composto pela sede municipal e Caxitoré, seu único distrito. Tejuçuoca situa-se a cerca de $140 \mathrm{Km}$ da capital Fortaleza, tendo como principal via de acesso a BR-222. Os limites municipais correspondem aos municípios de Itapajé e Irauçuba ao Norte; Irauçuba e Canindé ao Sul; General Sampaio, Apuiarés, Pentecoste e Itapajé a Leste; por fim Irauçuba a Oeste (CEARÁ, 2015).

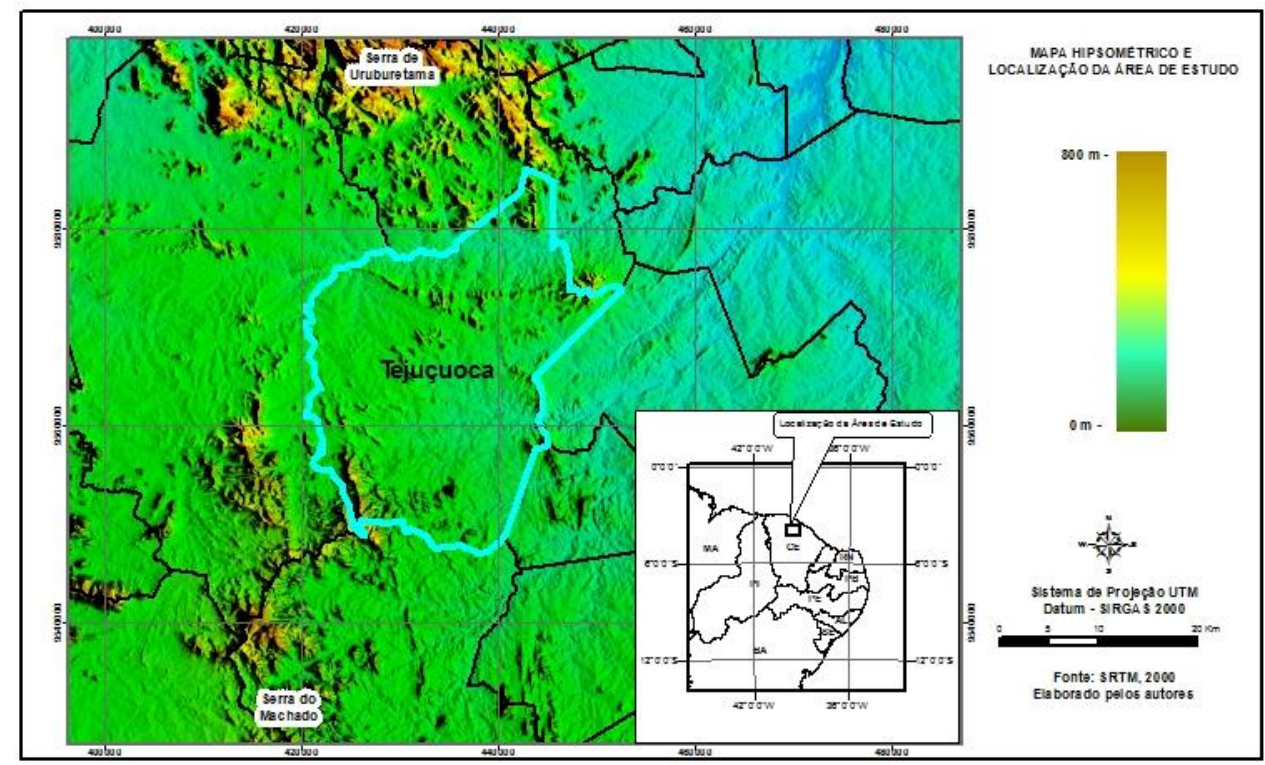

Figura 1: Localização do município de Tejuçuoca. Fonte: Autores 2016.

Para o entendimento de como se deu os processos naturais na evolução da paisagem no município de Tejuçuoca, se faz necessário o entendimento da dinâmica dos componentes ambientais.

Face ao exposto, o objetivo do referido trabalho é analisar de forma preliminar o quadro natural em que o município de Tejuçuoca está inserido, buscando caracterizar seus componentes ambientais, tais como a geologia, geomorfologia, climatologia, hidrologia, pedologia e seus aspectos fitogeográficos. 


\section{METODOLOGIA}

A referida pesquisa foi dividida em quatro etapas visando uma melhor organização e evolução do estudo para se chegar aos resultados almejados. A divisão das etapas se deu em levantamento bibliográfico/cartográfico, trabalhos de campo, trabalhos de gabinete com auxílio de técnicas de geoprocessamento e a integralização dos dados obtidos.

A primeira etapa consistiu em levantamentos bibliográficos de caráter interdisciplinar, onde se buscou por estudos já realizados no município de Tejuçuoca (MAPURUNGA, 2002; XIMENES, 2005). Já para os estudos setorizados, foram levantadas as bibliografias especializadas, sendo utilizadas bibliografias geológicas (BRITO NEVES, 1999; MABESSONE, 2002; CAVALCANTE e PADILHA, 2005; ARTHAUD, 2007), geomorfológicas (PEULVAST e CLAUDINO SALES, 2002), hidroclimáticas (NIMER, 1972; MOLION, 2002), pedológicos (EMBRAPA, 2006; LEPSCH, 2010) e fitogeográficos (FERNANDES, 2007).

No levantamento cartográfico, os mapas mais consultados para uma melhor interpretação da área em estudo foram o mapa geológico da CPRM (BRASIL, 2003) na escala de 1:500.000, o mapa morfoestrutural do Ceará e adjacências de Peulvast e Claudino Sales (2003) na escala de 1:500.000 e imagens Shuttle Radar Topography Mission - SRTM da área de estudo.

Foram realizados também dois campos na área em estudo, onde se tentou identificar o contraste entre diferentes períodos do ano, sendo que o primeiro campo no mês de outubro de 2015 estava marcado por um período de estiagem, e o mês de março de 2016 coincidiu com o período da quadra chuvosa.

Os trabalhos de gabinete foram de suma importância para a confecção da cartografia básica, onde contamos com o auxílio das técnicas de geoprocessamento e a elaboração de um climograma, com uma série histórica de 25 anos para a pluviosidade, com dados obtidos na Fundação Cearense de Meteorologia e Recursos Hídricos e 19 anos para a temperatura do município em questão com dados obtidos no Instituto Nacional de Meteorologia e, por fim, a última etapa foi a integralização dos dados obtidos em campo junto aos levantamentos bibliográficos/cartográficos, visando o melhor entendimento da área.

\section{RESULTADOS E DISCUSSÃO}

A área em estudo está inserida no setor Setentrional da Província Borborema, onde, seu passado geológico compreende uma complexa História evolutiva, marcado por processos tectônicos de aglutinações e dispersões de grandes massas continentais durante sua longa e ainda contínua evolução (MABESSONE, 2002), sendo quatro processos de fusão e quatro de fissão continental os responsáveis por sua atual configuração (BRITO NEVES, 1999). 
O município encontra-se no bloco tectônico denominado Domínio Ceará Central, onde seus limites correspondem à zona de cisalhamento Sobral-Pedro II a Oeste e a Leste pela zona de cisalhamento de Senador Pompeu (BRASIL, 2003). O Domínio Ceará Central, de acordo com Arthaud (2007), é formado principalmente por rochas do Complexo Ceará e da Unidade Acopiara.

A litoestratigrafia do Complexo Ceará é dividida, de acordo com Brasil (2003 op. cit.), em Unidade Canindé, Unidade Independência, Unidade Quixeramobim e Unidade Arneiroz. A área de estudo é constituída por rochas do Complexo Ceará, principalmente representada pelas Unidades Canindé e Independência, com primazia de litologias metamórficas.

A Unidade Canindé apresenta a maior abrangência espacial da área em estudo. De forma generalizada, predominam rochas metamórficas, tais como, paragnaisses, ortognaisses, migmatitos, lentes de quartzitos, rochas calcissilicáticas e calcários cristalinos (CAVALCANTE; PADILHA, 2005).

$\mathrm{Na}$ Unidade Independência também prevalece à ocorrência de rochas metamórficas, tendo como exemplos os xistos, quartzitos, gnaisses, calcários cristalinos (mármores) e rochas calcissilicáticas (CAVALCANTE e PADILHA, 2005 op. cit). Apesar de ser constituída por rochas metamórficas, a Unidade Independência apresenta um nítido controle geomorfológico no Estado do Ceará, com manutenção de topografias aguçadas elevadas, geralmente associadas a quartzitos, como nos casos das serras de Baturité e Machado. Os mármores da Unidade Independência possuem reflexos geomorfológicos muito expressivos, e em alguns casos com desenvolvimento de feições cársticas.

A Geomorfologia Regional da área em estudo compreende uma vasta superfície de aplainamento, denominada regionalmente como Depressão Sertaneja, e documenta o produto final da evolução geomorfológica dessa área a partir de ciclos erosivos em climas secos. Esta superfície é intercalada por relevos residuais como inselbergs, pequenas cristas e alguns esporões, estes representando continuidades das serras do Machado e Uruburetama. Existem também as planícies fluviais relacionadas ao rio Caxitoré, importante afluente do rio Curu e, por fim, os relevos cársticos.

A Depressão Sertaneja é a feição geomorfológica mais abrangente da área em estudo, e corresponde à superfície de aplainamento sobre rochas metamórficas da Unidade Canindé. De acordo com Peulvast e Claudino Sales (2002), essas superfícies constituem o resultado final da evolução de um relevo sobre a influência de diferentes sistemas morfoclimáticos. A Depressão Sertaneja local apresenta-se levemente ondulada a horizontalizada em alguns setores. 
A planície fluvial do rio Caxitoré localiza-se no setor ocidental do município de Tejuçuoca. Aparentemente, a planície apresenta uma sequência de terraços fluviais sobrepostos com presença expressiva de sedimentos aluviais, onde o rio Caxitoré demonstra ter claramente um condicionamento estrutural, pois em algumas áreas o rio segue drenando entre duas zonas de cisalhamento.

Os relevos residuais locais rompem a planura da depressão sertaneja e são caracterizados por sobressaltos topográficos, justificados por erosão diferencial, tendo em vista a maior resistência das rochas que os compõe. Comumente encontram-se inselbergs (Figura 2A), cristas e esporões representando continuidades dos maciços cristalinos do Machado e Uruburetama. É comum a ocorrência de microformas nos inselbergs, como a presença de taffoni ${ }^{l}$.

Os relevos cársticos (Figura 2B) aqui mencionados encontram-se na vertente setentrional da serra do Machado, num esporão da referida serra que, segundo Ximenes (2005), recebe localmente o topônimo de serra da Catirina e está localizado no extremo SW do município, apresentando-se como um relevo ruiniforme acima das superfícies sertanejas, possuindo topografias que se aproximam da cota $400 \mathrm{~m}$. O carste em questão localiza-se na reserva legal do assentamento Macaco e leva o nome de Parque Ecológico Furna dos Ossos.

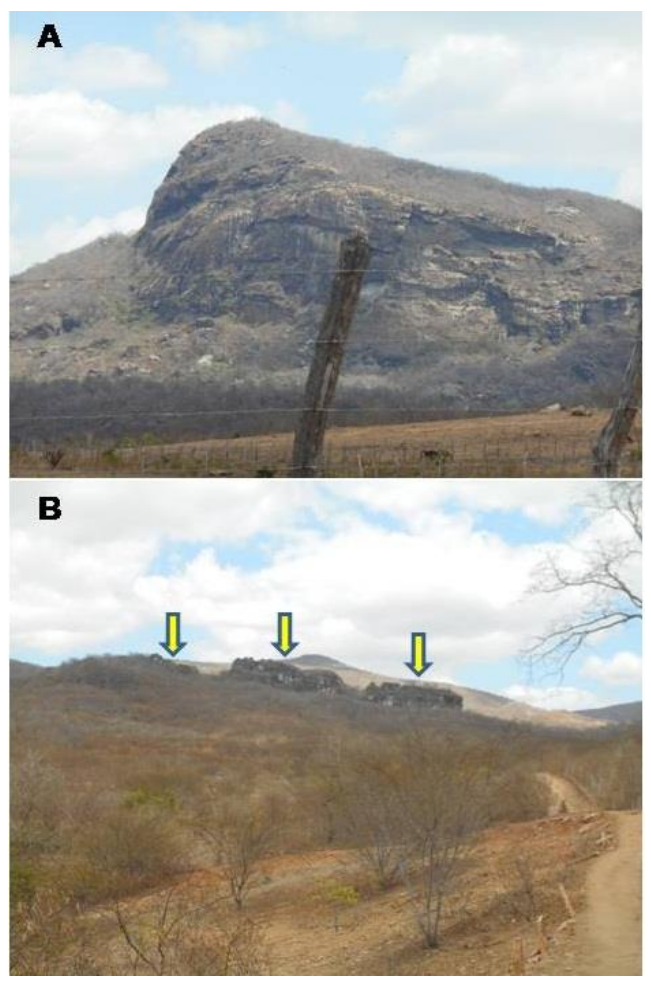

Figura 2: Em (A) exemplo de relevo residual, no caso, um inselberg com presença de Taffoni; Em (B) As setas em amarelo indicam onde ocorrem os relevos cársticos. Fonte: Autores (2015).

\footnotetext{
${ }^{1}$ Taffoni: São cavidades arredondadas que podem variar de decímetros a vários metros de diâmetro e profundidade, formadas por erosão em climas secos, sendo muito comum em rochas graníticas e areníticas. As cavidades menores de mesma origem são denominadas alvéolos (FOUCAULT e RAOULT, 2010).
} 
Os parâmetros hidroclimáticos de uma determinada região podem ser analisados a partir de diversas escalas de análise. Sob o ponto de vista latitudinal, podem ser interpretadas as relações da radiação solar com as temperaturas médias anuais. Já os totais pluviométricos devem ser analisados a partir de uma interpretação sobre os sistemas de circulação atmosférica de uma determinada região e seus reflexos anuais na delimitação temporal das estações chuvosas no ano.

Molion e Bernardo (2002) e Nimer (1972) afirmam que a Zona de Convergência Intertropical - ZCIT é o principal mecanismo responsável pelas chuvas que ocorrem no Norte do Nordeste Brasileiro. Em anos de seca, a ZCIT fica bloqueada mais ao norte que sua posição normal e em anos chuvosos, a ZCIT desloca-se até cerca de $5^{\circ} \mathrm{S}$.

O clima tem papel fundamental como agente morfogenético de qualquer relevo na superfície terrestre, com isso, tem-se ao longo da área em estudo, registros que documentam a ação do clima semiárido expressos no relevo em formas de relevos residuais, depósitos de tálus e superfícies de aplainamento.

No que tange os aspectos climáticos, o município de Tejuçuoca não difere muito do padrão predominante de clima semiárido nordestino e cearense, apresentando médias pluviométricas de $590 \mathrm{~mm}$, com pouca variação térmica ao longo do ano e concentração do regime das chuvas nos períodos de Fevereiro, Março e Abril, como pode ser observado na Figura $3 \mathrm{com}$ as médias de temperatura e pluviosidade.

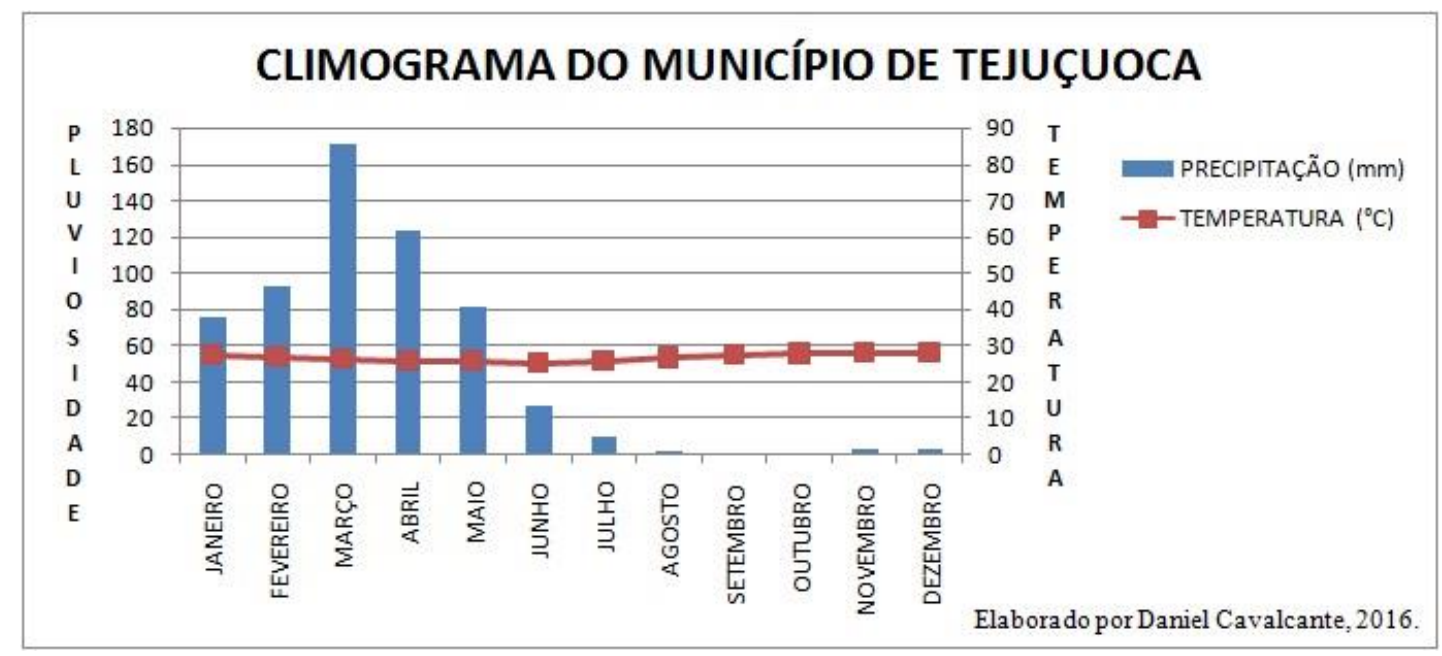

Figura 3: Climograma do município de Tejuçuoca com série histórica de 25 anos para a pluviosidade (1988 - 2015) e 19 anos para a temperatura (1995 - 2015). Fonte: FUNCEME (2016) \& INMET (2016).

Segundo Mapurunga (2002), os rios Caxitoré e Tejuçuoca são os dois principais rios do município de Tejuçuoca e possuem grande importância hídrica em termos locais. Nessa perspectiva, encontram-se relevantes açudes como, por exemplo, o Jereissati, o Tejuçuoca e o Jerimum. 
O rio Caxitoré é o principal rio do município e um notável afluente da bacia do Curu, localizando-se a W de Tejuçuoca, fazendo limites com o município de Irauçuba e drenando no sentido $\mathrm{N}$, até encontrar uma zona de cisalhamento indiscriminada, onde ele toma o direcionamento $\mathrm{E}-\mathrm{W}$, fazendo uma conversão de aproximadamente $90^{\circ}$ onde, provavelmente, passa a ter condicionamento estrutural, passando a fazer limites com o município de Itapajé.

No que diz respeito aos aspectos pedológicos, Lepsch (2010) destaca no Complexo Regional do Nordeste Brasileiro quatro subregiões com domínios de solos bem diferentes, onde essa diferença se dá por fatores climáticos: as subregiões são Meio Norte; Zona da Mata; Agreste; e Sertão.

Os solos de maior ocorrência na subregião do Sertão, que é onde está localizado o Estado do Ceará, são os Luvissolos Crômicos e Argissolos Vermelhos Eutróficos (nas porções intermediárias do relevo), os Neossolos Litólicos (nas partes mais altas do relevo) e onde o relevo é mais plano, coincidindo com as partes mais baixas, temos os Planossolos Nátricos e os Vertissolos (LEPSCH, 2010, op. cit).

De acordo com o mapa elaborado pela EMBRAPA (2006), no município de Tejuçuoca há quatro classes de solos predominantes, onde a distribuição está relacionada a aspectos climáticos e geomorfológicos, sendo eles os Planossolos, Luvissolos, Argissolos Vemelhos-Amarelos e Neossolos Litólicos. Cabe destacar que, em escala local, é possível constatar também a presença dos Neossolos Flúvicos.

Os Planossolos da área em estudo se encontram nos setores mais baixos do relevo, normalmente ocupando as depressões sertanejas, sendo este solo o de maior representação espacial, sendo caracterizado por uma pequena espessura, com limitações para o uso agrícola, sobretudo por problemas de drenagem.

Os Luvissolos têm uma menor expressão espacial se comparados aos Planossolos, mas também ocupam os setores mais baixos das depressões sertanejas, sendo estes, os que apresentam melhor drenagem, bem como presença de pedregosidade, que se caracteriza como fator limitante à mecanização.

Os Argissolos Vermelhos-Amarelos localizam-se no setor NE da área em estudo, e têm relativa representação espacial. Por serem eutróficos, possuem melhores condições de fertilidade, mas têm como limitação sua limitada profundidade.

$\mathrm{Na}$ área em estudo, os Neossolos Litólicos ocorrem por toda a extensão espacial, sendo comum encontrá-los vinculados a relevos residuais, tais como os inselbergs, nos esporões da serra do Machado e também nos esporões da serra de Uruburetama, sobretudo nos setores onde a declividade é mais expressiva. 
Nas planícies fluviais dos rios Caxitoré e Tejuçuoca, identificamos manchas de Neossolos Flúvicos. As várzeas do rio Caxitoré são utilizadas para a agricultura, tendo em vista sua topografia plana e maior disponibilidade hídrica.

A caatinga, de acordo com Fernandes (2007), é marcada por uma caducidade acima de $60 \%$ da sua queda foliar, além disso, expressa uma fisionomia garranchenta, apresentando espinhos e acúleos, e é marcada por características xéricas, e bastante difundido nas depressões sertanejas de Tejuçuoca.

No município de Tejuçuoca, de forma geral, nota-se uma expressiva queda foliar nos períodos de estiagem, caracterizada pela caducifolia da vegetação de caatinga e, nos períodos que coincidem com a concentração do regime das chuvas, que é Fevereiro, Março e Abril, ocorre uma explosão de cores verdes, marcadas pela quadra chuvosa.

Em Tejuçuoca a vegetação de caatinga (Figura 4) encontra-se bem conservada, sobretudo nos setores onde a topografia encontra-se mais acidentada, já que esse tipo de topografia dificulta o acesso de pessoas, diminuindo a ação antrópica predatória sobre os recursos naturais dessas áreas.

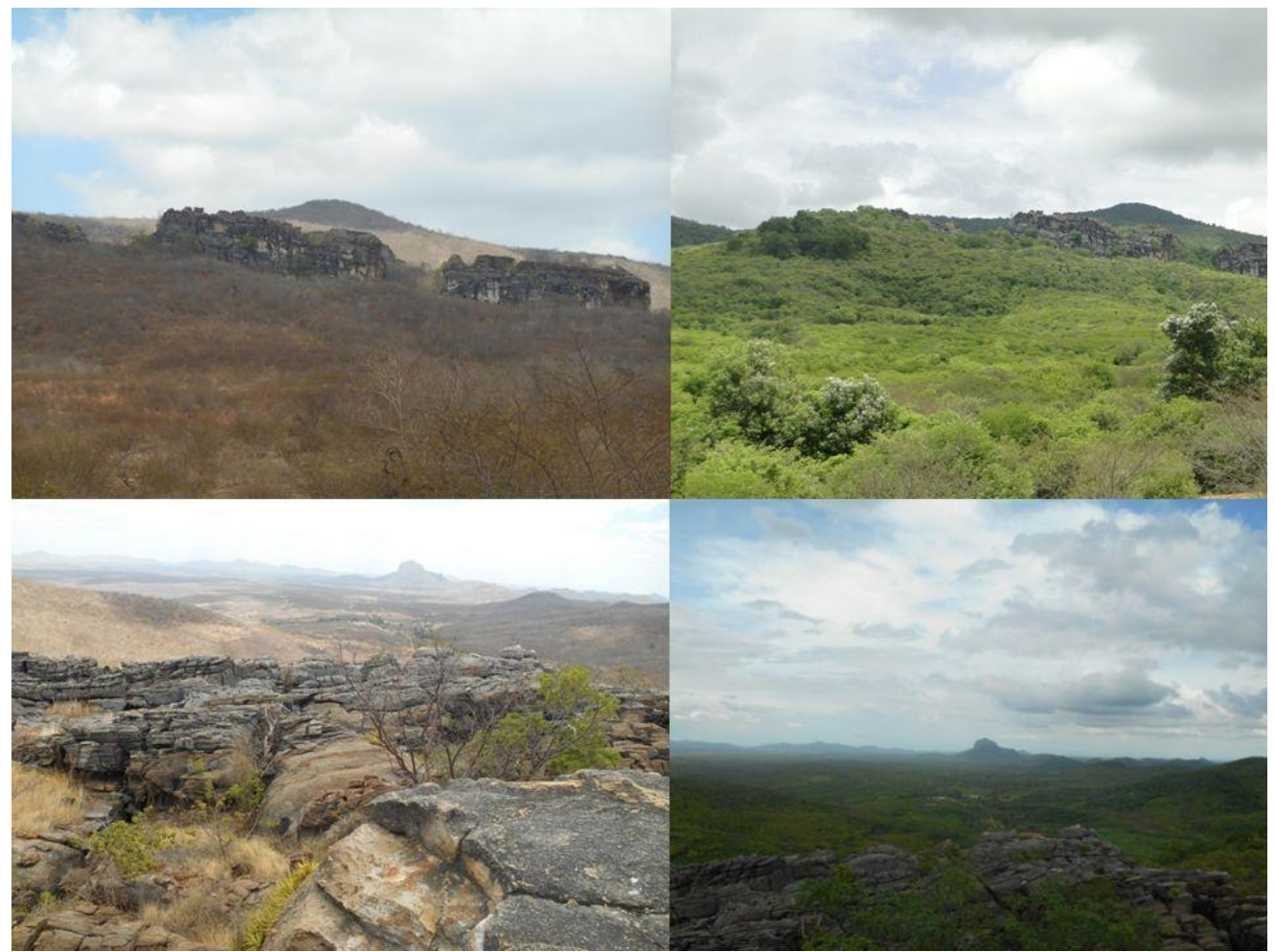

Figura 4: Aspectos da vegetação em diferentes períodos. Na esquerda, fotos tiradas em outubro de 2015 e na direita, fotos tiradas em março de 2016. Fonte: Autores (2015/2016).

As espécies de vegetação de caatinga arbórea mais representativas no município de Tejuçuoca são o juazeiro, angico, imburana e o pau branco. Já quando se trata das espécies 
vegetacionais de caatinga arbustiva, predominam o feijão bravo, camuru, jurema preta e o marmeleiro.

\section{CONSIDERAÇÕES FINAIS}

O referido estudo apresentou de forma sucinta uma caracterização de cada componente ambiental que compreende o município de Tejuçuoca, localizado no setor Centro-Norte do Estado do Ceará. Foram destacados os aspectos geológicos, geomorfológicos, condicionantes hidroclimáticos, os diferentes solos e a fitogeografia local.

Nesse contexto, Tejuçuoca apresenta uma dinâmica particular, onde na sua geologia há primazia de rochas metamórficas e seu relevo apresenta significativa heterogeneidade com feições erosivas, residuais e deposicionais. No que diz respeito aos aspectos hidroclimáticos, o referido município não foge a regra do contexto regional semiárido, porém, também apresenta um mosaico de solos bem variado e uma cobertura vegetal com representantes do bioma Caatinga bem conservada.

Desta forma, o presente estudo busca servir de base para estudos futuros mais aprofundados sobre as diversas temáticas ambientais no município de Tejuçuoca, tais como estudos geomorfológicos, zoneamentos, estratégias de ordenamento territorial, análises ambientais integradas, entre outros.

Apesar de a presente abordagem tentar fazer uma divisão dos componentes geoambientais, é importante destacar que existe uma relação sistêmica entre esses componentes, culminando na configuração das paisagens como conhecemos. Isso reforça a necessidade de se interpretar essas inter-relações e analisar o meio de forma holística ou integrada.

\section{REFERÊNCIAS}

ARTHAUD, M. H. Evolução neoproterozóica do Grupo Ceará (Domínio Ceará Central, NE Brasil): da sedimentação à colisão continental brasiliana. Tese de doutorado apresentado ao Programa de Pós Graduação em Geociências da Universidade de Brasília, 2007. 170 p.

BASTOS, F. H.; CORDEIRO, A. M. N. Fatores naturais na evolução das paisagens no semiárido brasileiro: uma abordagem geral. Revista Geonorte, v. 2, p. 464-476, 2012.

BRASIL. Companhia de Pesquisa de Recursos Minerais - CPRM. Atlas Digital de Geologia e Recursos Minerais do Ceará. Mapa na escala 1:500.000. Serviço Geológico do Brasil. Ministério das Minas e Energia. Fortaleza, 2003.

BRITO NEVES, B.B. America do Sul: Quatro fusões, quatro fissões e o processo acrescionário andino. Revista Brasileira de Geociências, Ano 1999, v. 29. São Paulo 1999. 
CAVAlCANTE, J. C.; PADILHA, M. W. M. Geologia e Mineração. In: VIDAL, F. W. H. et al (Org.). Rochas e minerais industriais do Estado do Ceará. Fortaleza: CETEM/ UECE/ DNPM/ FUNCAP/ SENAI, 2005. p. 9-18.

CEARÁ. Perfil Básico Municipal - Tejuçuoca. Instituto de Pesquisa e Estratégia Econômica do

Ceará (IPECE). Disponível no site <http://www.ipece.ce.gov.br/publicacoes/perfil basico/pbm2015/Tejucuoca.pdf.> Acesso em: 03/06/2016.

EMBRAPA. Solos UEP Recife, 2006. Disponível no site <http://www.uep.cnps.embrapa.br/solos/index.php?link=ce> Acesso em: 03/06/2016.

FERNANDES, A. Fitogeografia Brasileira-Fundamentos Fitogeográficos: Fitopaleontologia, Fitoecologia, Fitossociologia, Fitocorologia. $1^{\text {a }}$ Parte. Fortaleza: UFC, 2007.

FOUCAULT, A., RAOULT, J-F. Dictionaire de Géologie. Dunod. Paris, 2010.

LEPSCH, Igo F. Formação e conservação dos solos. São Paulo: Oficina de Textos, 2010.

MABESSONE, J. M. História Geológica da Província Borborema (NE Brasil). Revista de Geologia, v. 15, p. 119-129, 2002.

MAPURUnGA, G. M. P. Tejuçuoca: Potencialidade e Vocação Turística. Dissertação (Mestrado) - Universidade Estadual do Ceará. Fortaleza, 2002.

MOLION, L. C. B.; BERNARDO, S. O. Uma revisão da dinâmica das chuvas no Nordeste Brasileiro. Revista Brasileira de Meteorologia, v. 17, n. 1, p. 1-10, 2002.

NIMER, E. Climatologia da região Nordeste do Brasil. Introdução à climatologia dinâmica. Revista Brasileira de Geografia, v. 34, n. 1, p. 3-51, 1972.

PEULVAST, J. P.; CLAUDINO SALES, V. Carta morfoestrutural do Ceará e áreas adjacentes do Rio Grande do Norte e da Paraíba. Nota explicativa. In: CPRM: Atlas digital de geologia e recursos minerais do Ceará. Mapas na escala 1:500.000. Serviço geológico do Brasil, Fortaleza, 2003.

Aplainamento e geodinâmica: revisitando um problema clássico em geomorfologia. Revista Mercator, ano 2002, n. 1, Cidade: Fortaleza 2002.

XIMENES, C. L. Tejuçuoca: uma nova área espeleoturística no nordeste do Brasil. InformAtivo SBE - Sociedade Brasileira de Espeleologia, n. 90, p.22-23, jan./abr. 2005.

\section{AGRADECIMENTOS}

Agradeço à Universidade Estadual do Ceará, pelo apoio logístico que foi de suma importância para o desenvolvimento desse estudo. 
Recebido em: 14/05/2016

Aceito para publicação em: 01/10/2018 